\title{
ADMINISTRAÇÃO TRIBUTÁRIA E A NECESSIDADE DE UMA ÉTICA PARA O DESENVOLVIMENTO SUSTENTÁVEL ${ }^{1}$
}

\author{
TAX ADMINISTRATION AND THE NEED OF AN ETHICS FOR THE \\ SUSTAINABLE DEVELOPMENT
}

\author{
Vladmir Oliveira da Silva ${ }^{2}$ \\ Abner da Silva Jaques ${ }^{3}$
}

\begin{abstract}
RESUMO
A pesquisa tem por objetivo um estudo sobre as balizas e limites éticos e ficais da atuação da administração tributária. Nesse sentido, se justifica em razão da necessidade de se adequar o exercício do poder de tributar e a forma reguladora da ordem econômica para a tutela dos direitos humanos dos cidadãos contribuintes. A problemática consiste em verificar se a quarta dimensão dos direitos humanos engloba o dever do Estado em pautar o exercício de sua competência tributária também nos limites éticos, visando a concretização de uma sustentabilidade social. O método utilizado será o hipotético-dedutivo, a partir de pesquisas documentais e bibliográficas.
\end{abstract}

PALAVRAS-CHAVE: 1. Direito Internacional dos Direitos Humanos; 2. Estado ético fiscal; 3. Direito sustentável.

\section{ABSTRACT:}

This paper intends to study the tax administration's actions and its ethical and fiscal limits. Therefore, the present research is justified due to the need to adapt the power to tax and the economic order's regulatory form in order to protect citizens taxpayers' human rights. The problem, in this case, is to ascertain whether human rights' fourth dimension includes, or not, the State's duty to exercise its tax competence having an ethical limit, with the goal to achieve

\footnotetext{
${ }^{1}$ Esse artigo é resultado final de resumo expandido submetido, aprovado e apresentado durante a realização do VII Congresso Nacional da FEPODI. Em sua elaboração foram inseridas as orientações e propostas de discussões formuladas no Grupo de Trabalho (GT) "Direitos Humanos, Globalização e Sustentabilidade IV".

${ }^{2}$ Pós-doutor em Direito pela Universidade Federal de Santa Catarina - UFSC (2009). Doutor em Direito pela Pontifícia Universidade Católica de São Paulo (2006). Mestre em Direito pela Pontifícia Universidade Católica de São Paulo (2003), Graduação em Direito em (1997) e Graduação em Relações Internacionais pela mesma Universidade (2000). Professor Titular na Universidade Federal de Mato Grosso do Sul - UFMS. Professor da Pontifícia Universidade Católica de São Paulo - PUC/SP. Foi Secretário Executivo (2007-2009) e Presidente (2009-2013) do Conselho Nacional de Pesquisa e Pós-Graduação em Direito (CONPEDI - Sociedade Científica da Área o Direito). E-mail: vladmir@aus.com.br. Lattes: http://lattes.cnpq.br/5229046964889778

${ }^{3}$ Mestrando em Direito pela Fundação Universidade Federal de Mato Grosso do Sul (UFMS), com bolsa CAPES. Graduação em direito pela Universidade Católica Dom Bosco (2018). Pós-graduando em direito tributário pelo Instituto Brasileiro de Estudos Tributários, em Mato Grosso do Sul (IBET/MS). Pós-graduando em Direito Ambiental, Agrário e Urbanístico pela UNISC, em parceria com a CFOAB/ENA. Presidente da Comissão de Incentivo à Produção Científica e Jurídica da Ordem dos Advogados do Brasil, Seccional de Mato Grosso do Sul (CIPCJ/OABMS). E-mail: abnersjaques90@gmail.com. Lattes: http://lattes.cnpq.br/4301394075729145
} 
the social sustainability. For this purpose, we used the hypothetical-deductive method, with a documentary and bibliographic research.

KEYWORDS: 1. International human rights la; 2. Ethical tax state; 3. Sustainable Law.

\section{INTRODUÇÃO}

Na evolução e construção dinâmica dos direitos humanos reconhece-se a dignidade humana enquanto valor supremo, que é inestimável e distingue cada ser humano. Nesse sentido, para a preservação dos direitos relativos a cada dimensão (liberdades, igualdade e solidariedade) não há mais espaço para uma concepção individualista de agentes, mas se exige uma atuação ética e conjunta de todos (públicos e privados) no sentido de colocar o ser humano no epicentro de todo um sistema.

Essa premissa também deve ser aplicada ao Estado em seu exercício do poder de tributar, visando equalizar uma relação direta com os cidadãos que seja capaz de preservar direitos de liberdade, igualdade e de solidariedade. Desse modo, a presente pesquisa tem por objetivo um estudo sobre a ética na atuação da Administração Tributária para incentivo ao desenvolvimento sustentável.

A problemática deste estudo consiste em aferir se a quarta dimensão dos direitos humanos engloba o dever do Estado na adequação do exercício de sua competência tributária também nos limites éticos, visando a concretização de uma sustentabilidade social. A justificativa fica evidente tendo em vista a necessidade de se compatibilizar o exercício do poder de tributar e a atuação do Estado na ordem econômica para o efetivo desenvolvimento com a tutela da dignidade humana e em prol da sustentabilidade.

Para a construção da pesquisa, o primeiro abordará a evolução e construção dos direitos humanos até o reconhecimento de novos valores insurgentes em uma quarta dimensão no processo de dinamogenesis. Posteriormente, no item dois será tratada a doutrina humanista do direito econômico, que observa pela necessidade de relações da ordem econômica na perspectiva não do acumulo de riquezas, mas sim da tutela da existência digna de todos cidadãos. Já no item final, em que repousa o aspecto principal da pesquisa, será buscada uma concepção ética de atuação do Estado no exercício do poder de tributar, capaz de relacionar as suas atividades e dos particulares no exercício de atividades econômicas e estabelecer um diálogo na tutela dos direitos de primeira, segunda e terceira dimensão.

O método utilizado será o hipotético-dedutivo, em que a hipótese principal é a de que a quarta dimensão dos direitos humanos também exige uma atuação ética e responsável do 
Estado no cumprimento de suas atividades. Valer-se-á, para tanto, de pesquisas documentais e bibliográficas, a fim de construir as balizas e limites éticos e fiscais da administração tributária.

\section{A QUARTA DIMENSÃO NO PROCESSO DE DINAMOGENESIS DOS DIREITOS HUMANOS}

A evolução e construção dos direitos humanos se trata de um processo lento, imprevisível e de resistência, que observa valores necessários de tutela em determinado momento histórico da sociedade, sobretudo quando insurgente para preservação ou reafirmação da dignidade e da pessoa humana ${ }^{4}$ (SILVEIRA; ROCASOLANO, 2010). Em razão da dificuldade em precisar o momento correto de surgimento de uma concepção acerca da existência de um determinado direito até então abstrato na história, os conceitos de dignidade e direitos humanos foram moldados em conformidade com a cultura e a expressão das sociedades à época (TRINDADE, 2003).

Há fatores importantes para a identificação de uma valoração da pessoa humana no período axial, especialmente os formulados pelos profetas de Israel em relato bíblico, na qual em defesa de uma religião monoteísta - colocava os seres humanos à imagem e à semelhança de Deus e, portanto, com atributos transcendentes capazes de dominar todos os demais seres vivos e a natureza (COMPARATO, 2010).

Outro ponto relevante para a identificação de uma ideia de dignidade humana, por exemplo, pode ser verificada a partir do Imperativo Ético de Immanuel Kant, cuja compreensão repousava sobre a ideia de autonomia dos seres humanos para construírem seus destinos ${ }^{5}$ (COMPARATO, 2010).

Sob essas perspectivas, tem-se a dignidade humana enquanto valor inestimável a todos os seres humanos; contudo, é difícil estabelecer uma uniformidade conceitual, justamente porque varia conforme a sociedade e o tempo em que é observada. Nessa linha de ideias, para

\footnotetext{
${ }^{4}$ Esse processo é denominado de Dinamogenesis e que serve para "[...] expressar o desenvolvimento e o reconhecimento dos direitos humanos nas estruturas sociais, por que eles são positivados em textos normativos e porque são criadas instituições para garanti- los [...]. No processo da dinamogenesis, a comunidade social inicialmente reconhece como valioso o valor que fundamenta os direitos humanos (dignidade da pessoa humana). Reconhecido como valioso, este valor impulsiona o reconhecimento jurídico, conferindo orientação e conteúdos novos (liberdade, igualdade, solidariedade, etc.) que expandirão o conceito de dignidade da pessoa. Essa dignidade, por sua vez, junto ao conteúdo dos direitos humanos concretos, é protegida mediante o complexo normativo e institucional representado pelo direito" (SILVEIRA; ROCASOLANO, 2010, p. 199).

${ }^{5}$ Aqui certamente há uma concepção antagônica de dignidade, pois muito embora a formulação de Kant parta da concepção de dignidade em razão da racionalidade, a dignidade bíblica advém de uma intervenção divina, que tem o condão de atribuir a dignidade como forma de reconhecimento da semelhança e da relação dos seres humanos com Deus. De qualquer sorte, a intenção foi evidenciar uma preocupação quanto à identificação de uma dignidade na história, seja ela transcendente ou imanente.
} 
o presente estudo, filia-se ao conceito de dignidade compartilhado por Pérez Luño (2010) e Ingo Sarlet (2001), que a entendem na condição de qualidade intrínseca e distintiva de cada ser humano, capaz de protegê-lo contra tratamentos degradantes - seja de ordem física ou moral e que garante condições mínimas de sobrevivência.

Desse modo, ainda que em uma ideia abstrata, a dignidade se configura com base em um entendimento lógico e individual, que reconhece cada ser humano como um agente que possui valor ${ }^{6}$, seja ele transcendente ou imanente. A axiologia advém de uma consideração enquanto um princípio geral e/ou fundamental no direito internacional - e não de um direito autônomo inscrito -, que é carreada especialmente por um conteúdo ético relevante, elementar para o desenvolvimento e construção de seu próprio conteúdo.

Nesse ponto, são válidas as observações de Bobbio (2004), para quem o problema dos direitos humanos não está em verificar uma justificativa e um conceito formador da dignidade - até porque há muito já foi reconhecida enquanto supra valor -, mas sim em oferecer a devida tutela em relação aos próprios direitos transdimensionalmente já reconhecidos, especialmente no aspecto de internacionalização, de modo que leva a crer que a dignidade não é uma dificuldade no aspecto filosófico, mas sim político, pois sempre imprescinde, para o reconhecimento de um novo valor, de lutas e resistências (SILVEIRA; ROCASOLANO, 2010).

Bobbio (2004, p. 25), corroborando com a ideia de que a evolução e o surgimento de (novos) direitos humanos se dão de forma lenta, dolorosa e imprevisível, afirma que: "Os direitos do homem, por mais fundamentais que sejam, são direitos históricos, ou seja, nascidos em certas circunstâncias, caracterizados por lutas em defesa de novas liberdades contra velhos poderes, e nascidos de modo gradual"7. É por esse motivo que Silveira e Rocasolano (2010, p. 95) sustentam que "[...] os direitos humanos são uma forma de controlar e reduzir o poder estabelecido mediante sujeição do poder aos ditames do direito", especialmente se verificado que historicamente sempre surgem novas formas de manifestação e manutenção do poder.

Assim, no processo dinamogênico dos direitos humanos há um evidente confronto entre domínio e a própria pretensão de evolução desses direitos, que resultam em resistências e lutas em favor da preponderância e da tutela dos direitos já reconhecidos ou de novos (PIOVESAN, 2010). Silveira e Rocasolano (2010, p. 99) destacam que o processo de antagonismo entre poder e evolução dos direitos humanos se repete em relação aos direitos de

\footnotetext{
${ }^{6}$ É partindo dessa compreensão, por exemplo, que Karl Marx formula a ideia de reificação dos seres humanos e abomina qualquer instrumentalização na condição de engrenagem de um sistema.

${ }^{7}$ A mesma ideia é reafirmada por Piovesan (2010, p. 114), para quem a evolução histórica dos direitos humanos "[...] não representa um dado, mas um construído, uma invenção humana em constante processo de reconstrução, [sendo eles] frutos de um espaço simbólico de luta e ação social, na busca da dignidade humana".
} 
primeira, segunda e terceira dimensão ${ }^{8}$ - e se opõe, com certeza, à pretensão de reconhecimento de um novo valor preponderante capaz de justificar uma quarta dimensão dos direitos humanos:

[...] a teoria do poder está e esteve presente durante todas trajetória dos direitos humanos - desde antes de seu reconhecimento, quando preponderavam construções negadoras desses direitos, passando pelos direitos de primeira geração (com a afirmação e garantia dos direitos de autonomia e participação) e de segunda geração (com a tutela e enfrentamento sobre a real eficácia dos direitos prestacionais), até o debate atual sobre os direitos da solidariedade, que envolvem tópico tão complexos com a paz, a democracia e o desenvolvimento sustentável.

Os direitos de primeira dimensão, relacionados à liberdade do indivíduo, advieram da necessidade de contenção do poder absolutista - em termo políticos -, cuja expressão de reconhecimento maior advém da Declaração dos Direito do Homem e do Cidadão (1789), que busca a garantia dos direitos civis e políticos. Já a igualdade, enquanto valor preponderante da segunda dimensão, nasceu em razão de inconformismo de desigualdades durante o liberalismo econômico, dando azo aos direitos sociais, econômicos e culturais, utilizáveis não sob uma perspectiva individual, mas sim coletiva, evidenciados, sobretudo, a partir da Constituição de Weimar (1919), que buscou prelecionar a igualdade material e ideias de justiça social; por fim, a terceira dimensão (direitos de solidariedade) busca congregar um responsabilidade conjunta com a finalidade de garantir a paz - justamente porque emergiu no período pós-guerra, junto à criação da ONU, em 1948 -, a democracia e a solidariedade ou fraternidade, impondo uma perspectiva difusa de direito, destinados a todos os agentes, de todas as nações (COMPARATO, 2010).

Muito embora a classificação de direitos se dê em dimensões para melhor alocá-las no período e distribuir seu conteúdo axiológico, pondera-se que direitos humanos são indivisíveis, ou seja, compreendidos em um bloco de valores, na qual a ofensa ou desrespeito a um direito de uma determinada é capaz de influir diretamente em direitos de outra classificação (PIOVESAN, 2002). Um exemplo consiste em ofensa ao meio ambiente (direito de terceira dimensão), cujo reflexo poder afetar o direito à saúde, ao ambiente de trabalho equilibrado, entre outros, que estão na segunda dimensão dos direitos humanos.

Na medida em que processo de dinamogenesis representa - após o reconhecimento da de valores necessários de proteção - uma ampliação dos direitos humanos em detrimento de um poder, é necessário salientar que sempre diante do surgimento de uma esfera da dignidade

\footnotetext{
${ }^{8}$ Neste ponto, opta-se pela expressão "dimensão" ao invés de "geração", pois como bem explicam Rocasolano e Silveira (2011, p. 69-70), as dimensões dos direitos humanos se completam, na medida em que aqueles mais recentes tomam como pressuposto ou ponto de partida os anteriores, especialmente para conseguir explicar sua relevância no cenário jurídico. Contudo, é de se reconhecer que não se pode chamar de despicienda a 'teoria das gerações dos direitos humanos', uma vez que a partir dela é possível identificar - e melhor explicar - os fatos históricos relevantes e os protagonistas que atuam na formação de uma nova' geração/dimensão'.
} 
humana que demande tutela será possível assim o reconhecimento de uma nova classificação, desde que estejam presentes os valores de tutela, um conteúdo e uma categoria de direito preponderante (SILVEIRA, ROCASOLANO, 2010).

No atual contexto da globalização ${ }^{9}$ - remontando-se ao período final do século XX em diante -, em que é possível uma integração ligeira de pessoas, do mercado, da intensificação do consumo e da prestação de serviços, da evolução das tecnologias, de práticas capitalistas, da alteração e do compartilhamento de culturas, tem-se uma nova deflagração de poder que, em razão do atual estágio social, finda por ser desfragmentado e, portanto, de maior dificuldade para resistência.

Não apenas isso, mas como observa Bauman (1999), a globalização é um período paradoxal, porquanto impõe uma relação de causa e consequência, na qual finda por ser “"[...] muito benéfica para muito poucos, mas [que] deixa de fora ou marginaliza dois terços da população mundial", pois seus benefícios servem precipuamente para auxiliar os mais ricos, na medida em que são eles que podem “[...] movimentar largas somas de dinheiro mundo afora com extrema rapidez e especular com eficiência cada vez maior” (BAUMAN, 2001, p. 141).

Como efeito da globalização, a preocupação com uma comunidade internacional capitalista e neoliberal, sobretudo na ideia de que a mão invisível do mercado é apta à correção de distorções - o capitalismo apresentado enquanto poder incontestável, que submete a ele toda a vida humana -, impõe a necessidade de ampla observação e de novos debates sociais, uma vez que o aspecto social e solidário do mercado tem sido deixado à margem, ocasionando em, por exemplo, marginalização da pobreza, degradação do meio ambiente, exclusão social, entre outros, que representa a instrumentalização do sistema econômico neoliberal para negar direitos humanos (BOBBIO, 2004).

Salienta-se que muito embora o capitalismo seja expressão dos direitos de primeira dimensão e, portanto, merecedor de tutela, faz-se necessário uma nova análise e uma modulação de seus efeitos, a fim de compreender uma confluência direta com os direitos de segunda e terceira dimensão (SAYEG, BALERA, 2011). Assim, em detrimento da subversão desse sistema enquanto poder é que surgem, no estágio atual da sociedade, novas demandas por meio

\footnotetext{
${ }^{9}$ Para fins do presente estudo, entende-se por globalização “[...] proceso amplio, contradictorio, complejo, heterogéneo y profundo de cambio en las relaciones entre sociedades, naciones y culturas que ha generado una dinámica de interdependencia en las esferas económica, política y cultural, en las que se desenvuelve el actual proceso de mundialización y que hace posible que acontecimientos, decisiones y actividades ocurridas en un determinado lugar del planeta repercutan de forma muy significativa en otros lugares, en otras sociedades y en otras persona". (TORRADO, 2000, p. 47).
} 
do processo dinamogênico tendente a reconhecer a necessidade de limitação de um poder existente.

Não há dúvidas que as preocupações hodiernas advindas das práticas de mercado apresentam a necessidade do reconhecimento de novos horizontes axiológicos capazes de tutelar valores ambientais, políticos, jurídicos, culturais, sociais, entre outros. Isto porque, a globalização tem se apresentado como um fenômeno que provoca desigualdade social, desemprego, instrumentalização do meio ambiente e ofensa ao direito de desenvolvimento, sendo assim uma forma manifesta de poder capaz de ofender os direitos humanos, especialmente aqueles que são considerados 'sofredores', na concepção de Bauman (2011, p. 81):

\begin{abstract}
Nada pode ser feito para conter - para reverter a globalização. [...] Entretanto, muita coisa depende de nosso consentimento ou de nossa resistência de forma enviesada até agora assumida pela globalização do compromisso humano. [...] No interior da densa rede mundial de interdependência global, não podemos estar seguros de nossa inocência moral sempre que outros seres humanos sofram por falta de dignidade, miséria ou sofrimento. Não podemos declarar que não sabemos, nem ter certeza de que não haja nada que possamos mudar em nossa conduta para evitar ou, pelo menos, aliviar a sorte dos sofredores.
\end{abstract}

A globalização não tem se mostrado temerosa apenas em relação à revolução econômica e do sistema de mercado, mas também com as evoluções tecnológicas e da biogenética $^{10}$, que findam por subjugar o valor da natureza e do próprio ser humano, configurando-se, assim, uma nova demanda de preponderância axiológica "[...] que se direciona para o reconhecimento de direitos que só cabem serem classificados como de quarta geração [dimensão]" (BOBBIO, 2004, p. 229). Nesse sentido, inclusive, a dimensão da solidariedade, ao propor uma ideia de cooperação na defesa dos direitos humanos, se mostra insuficiente para alcançar o tratamento de alguns dos efeitos da globalização, o que insurge na necessidade de reconhecimento de uma nova classificação que crie e integre novos valores.

Assim, a quarta dimensão surge da necessidade de tutela de valores em razão das inovações tecnológicas e dos riscos ao desenvolvimento. Frise-se que a preponderância de valor em uma nova classificação se consubstancia no reconhecimento de uma ética e de uma responsabilidade para a coletividade em detrimento do próprio indivíduo, ou seja, adota como premissa uma análise indutiva, partindo dos costumes próprios para identificar e valorar o que

\footnotetext{
${ }^{10}$ Ao dispor acerca das pesquisas biológicas enquanto valores preponderantes em uma quarta dimensão, Bobbio (2004, p. 25) assevera que: “[...] Mas já se apresentam novas exigências que só poderiam chamar-se de direitos de quarta geração, referentes aos efeitos cada vez mais traumáticas da pesquisa biológica que permitirá manipulações do patrimônio genética de cada indivíduo".
} 
seja bom para o grupo social e, doravante, consolidá-lo enquanto norma de comportamento (BRITO, 2013).

A dificuldade, nesse ponto, consiste em identificar qual o padrão ético a ser evocado. Melhor explicando: se partiria em razão da solidariedade e do desenvolvimento enquanto valores da terceira dimensão ou se a ética da coletividade em si mesma seria suficiente para atender as necessidades de um grupo.

Para Silveira e Rocasolano (2010, p. 182), por exemplo, no que diz respeito às pesquisas científicas, a premissa da ética consubstanciaria na condição de "[...] um novo valor que concretiza a dignidade humana para além da solidariedade". Portanto, ter-se-ia que contemporaneamente seria possível um equilíbrio além da dimensão da solidariedade, mas com vistas à preservação da primeira e segunda dimensão. Importa dizer, portanto, que a ética ou a responsabilidade científica enquanto valores preponderantes em uma quarta dimensão se comunicam diretamente na preservação e observância das primeiras dimensões, mas com uma perspectiva difusa e intergeracional preocupada com o futuro.

No seio da quarta dimensão tem-se a responsabilidade e a ética enquanto valores preponderantes, cujo conteúdo de direitos se faz presente em favor da segurança, frente aos riscos da modernidade ao desenvolvimento. Assim, tais quais os direitos de terceira dimensão, busca-se a tutela difusa, mas agora sob uma perspectiva de horizontalidade dos direitos humanos fundamentais, capaz de justificar a ideia de um Estado Necessário ou Ético de Direito.

\section{PERSPECTIVA HUMANISTA NA ORDEM ECONÔMICA}

A adoção de uma perspectiva ética para a proteção dos direitos humanos na época da globalização influência em reflexões críticas de várias áreas da sociedade. É por esse motivo que Castells (1999) a considera como um fenômeno revolucionário, na medida em que tem o condão de afetar todas as esferas da sociedade, sobretudo o social e o sistema jurídico. Neste ponto do trabalho, serão observadas suas expressões no direito econômico ${ }^{11}$ e sua relação com o direito ao desenvolvimento.

\footnotetext{
11 Adota-se como conceito de direito econômico aquele apresentado por Silveira (2006, p. 120): “O direito econômico configura-se como um novo ramo do direito, que interage com os demais de forma integrativa, no intuito de materializar os direitos fundamentais na órbita da metaindividualidade, garantindo do formal até o material, de acordo com o regime econômico adotado por cada país. Com efeito, pode-se dizer que os seus sujeitos são os participantes do mercado, sejam eles empresas, indivíduos, grupos econômicos, o Estado-governo e, principalmente o povo, entendido como as coletividades que devem ser protegidas. E o seu objeto configura-se na busca da efetividade da função social da economia, todavia variando o seu conteúdo de acordo com o regime econômico adotado por cada país. Portanto, até mesmo nos países liberais, ele será objeto do direito econômico, ou seja, a opção por um direito negativo - o direito da não disciplina/intervenção da economia pelo direito".
} 
Em primeiro momento, sem prejuízo às circunstâncias históricas anteriores ${ }^{12}$, parte-se da ideia de que o direito econômico passou a deter autonomia e características próprias para lhe conferir um atributo de ramo do direito após a Segunda Guerra Mundial, em que o desenvolvimento passou a ser pauta prioritária das Nações ${ }^{13}$. Esse reconhecimento também se deu em razão da Declaração e do Pacto Internacional dos Direitos Econômicos, Sociais e Culturais de 1966, que buscaram estabelecer direitos capazes de garantir as necessidades básicas dos cidadãos, sendo esse construto importante para que posteriormente fosse consolidada a Declaração sobre o Desenvolvimento, em 19866 (SILVEIRA; ROCASOLANO, 2010).

O direito econômico no plano internacional advém muito da ruptura com a concepção clássica de Estado Nação ${ }^{14}$ e o reconhecimento da necessidade de preservação de direitos humanos com base em uma atuação conjunta dos agentes internacionais, que se consubstancia em uma relação de horizontalidade na busca da efetivação e implementação de garantias de direitos ${ }^{15}$. Acerca do assunto, Sayeg e Balera (2019) salientam que: “[...] não obstante o caráter individualista das poderosas forças do mercado, se contemplará a efetivação multidimensional dos Direitos Humanos com vistas à satisfação universal da dignidade da pessoa humana e do Planeta, tendo por plataforma a ideia de um futuro comum".

Em face às demandas evolutivas no campo econômico, sobretudo no que diz respeito ao protagonismo do sistema capitalista na virada do século XIX - quando passou a ocorrer o agrupamento de agentes privados e, por consequência, a concentração do capital em favor de minorias e o aumento de poder social de grandes empresas (SILVEIRA, 2006) -, viu-se a necessidade de conjugar novos elementos, sejam eles políticos ou jurídicos, capazes de atribuir uma relação equilibrada e de perseguir os interesses da coletividade, porquanto “[...] os

\footnotetext{
${ }^{12}$ Diversas são as situações históricas que evidenciam o surgimento de um direito econômico. Dentre elas, podemse destacar: a) a ruptura da monarquia absolutista na Inglaterra, muito em razão de atritos com a nobreza latifundiária; b) a Declaração dos Direitos do Homem e do Cidadão, de 1789, que destacou pela proeminência de direitos sociais; c) As alterações, em 1789, na Constituição Americana para inclusão do plano Bill of Rights; entre outros.

${ }^{13}$ Com a finalidade de corroborar esse entendimento, Silveira (2006) destaca o surgimento do Fundo Monetário Internacional (FMI) e do Acordo Geral sobre Tarifas e Comércio (GATT).

${ }^{14}$ Conforme observam Silveira e Jaques (2019), “[...] o Estado-Nação, enquanto centro da teoria bodiniana pressupõe que a soberania de um Estado (no plano internacional) não pode ser partilhada sob pena de resultar em uma condição de anarquia e, portanto, em sua própria destruição. Isto porque, na concepção de Bodin (1951), a manutenção da República consiste na relação em que poucos devam mandar e os demais obedecer, de modo que apenas seria possível a instauração e garantia de uma ordem social em caso de um poder central que goze da prerrogativa de direitos exclusivos e possa impor sua soberania sobre qualquer outro Estado".

${ }^{15}$ Nesse sentido, Jaques e Silveira (2019), ao analisarem essa horizontalidade na perspectiva de Peter Haberle, em sua obra 'Estado Constitucional Cooperativo', ponderam que: "Haberle (2007) defende que o conceito de soberania seja partilhada em favor do bem comum. Ou seja, na concepção de referido autor, é necessário que todos os Estados reconheçam a necessidade de preocupações em comum e, desta maneira, atuem em conjunto para cumprir suas funções”.
} 
instrumentos jurídicos gerados pela crença numa ordem racional eterna, arraigada na ordem racional humana perene, não se mostravam adequados para a solução dos problemas decorrentes da materialidade da ordem econômica” (FONSECA, 2004, p. 8).

Nessa esteira, Silveira (2006) pondera pela condição de um caráter de interesse público da economia, em que o Estado passa por uma transição que precisa deixar de atuar diretamente no plano econômico para assumir a função de regulador jurídico das relações, visando atender uma justiça social, incentivar o desenvolvimento e compatibilizar o exercício de direitos econômicos, culturais e sociais com os direitos civis e políticos.

Essa perspectiva consiste na tentativa de delimitar o capitalismo por meio de uma forma capaz de elevar o mercado "[...] a uma economia humanista de mercado para satisfação universal do direito objetivo inato, correspondente à dignidade da pessoa humana em suas dimensões de democracia e paz" (SAYEG; BALERA, 2011, p. 14). Ao abordar o assunto, Silveira (2006, p. 123-124) explica o humanismo de modo mais acentuado:

[...] o objeto do direito econômico corresponde aos direitos humanos econômicos como valores fundamentais que tenham por fim assegurar, inter alia, igualdade de oportunidades econômicas para todos, em relação ao acesso aos recursos básicos, educação, serviços de saúde, alimentação, moradia, emprego, distribuição de renda, entre outros na esfera do Estado-nação, assim como implementar e garantir, no âmbito do direito internacional público, a autodeterminação dos povos, mediante o desenvolvimento e a livre disposição das suas riquezas e de seus recursos naturais, em respeito às obrigações decorrentes da cooperação econômica internacional, fundamentadas no princípio do proveito mútuo e dos demais do direito internacional público. Trata-se portanto de uma visão doutrinária que busca restaurar, na análise econômica, a condição do homem como medida de todas as coisas e centro do universo. Dessa forma, a teoria humanista pretende restabelecer na economia a ordem natural das coisas, onde a lei é o meio e homem o fim.

Denota-se que a preocupação da doutrina humanista consiste em buscar meios de garantir o desenvolvimento, bem-estar da coletividade e a proteção dos direitos humanos, independente da dimensão, a partir da regulação do direito econômico. Nessa perspectiva, o homem é visto como um fim em si mesmo em razão da qualidade intrínseca e diferencial que o protege, que é a dignidade humana. Portanto, “[...] funciona assim como uma espécie de direito preservador ou corretivo do sistema econômico, que não abre mão da ética e dos valores da sociedade, ao mesmo tempo que trabalha ao lado da economia" (SILVEIRA, 2006, p. 124).

Essa perspectiva pode ser visualizada no direito brasileiro, pois a ordem econômica tem sua fundação em dois pilares, que são, consoante a disciplina do artigo 170, da Constituição Federal, a livre iniciativa e a valoração do trabalho humano (BRASIL, CRFB, 1988); ou seja, há uma perspectiva de capital-trabalho - que sustenta um modelo econômico capitalista delimitada pelo reconhecimento de uma necessidade de existência digna. Desse modo, Silveira (2006, p. 98) bem destaca que o direito econômico interno “[...] possui uma clara preocupação 
com a dignidade humana, que na Constituição apresenta-se como um princípio estruturante e que germina nessa ordem”, por meio da perseguição de uma justiça social (SILVEIRA, 2006, p. 98).

A adoção desses pilares dá ensejo ao reconhecimento de aplicação de um ideal humanista e finalístico que vincula a atuação do Estado e dos demais agentes privados à preservação de valores sociais. Sobre o assunto, Silveira (2006, p. 149) pondera que sob o pálio da Constituição econômica se "[...] pretende, em última instância, a inclusão social, mesmo que para isso tenha que intervir no âmbito econômico, seja em face do interesse privado ou do Estado-governo".

Nesse sentido, os princípios ${ }^{16}$ destacados no artigo 170, da Constituição Federal, que devem ser observados para assegurar a todos uma existência digna por meio da ordem econômica brasileira, evidenciam uma estrutura adotada pelo legislador constituinte para vincular o Estado e os particulares na concretização humanista de suas atividades. A partir deles, é possível visualizar indicações que consagram bases de desenvolvimento - tanto da ótica do Estado, das Empresas e dos cidadãos -, na medida em que atribuem uma função às atividades lucrativas.

Observe-se, por exemplo, a busca pela erradicação da pobreza ou pela redução de desigualdades, que se comunicam diretamente com a concretização de direitos sociais e coadunam com a ideia de desenvolvimento integral e sustentável, que nos últimos anos vem sendo perquirida ${ }^{17}$.

Desse modo, tem-se, na visão de Silveira (2006), a adoção constitucional não de “[...] tutela da riqueza, mas sim da população, isto é, da existência digna de todos, conforme os ditames da justiça social”, destacando que o desenvolvimento econômico deve compreender em seu epicentro, a partir de uma constituição econômica, alguns direitos, tais como: a) a

\footnotetext{
${ }^{16}$ Os princípios são: “I - soberania nacional; II - propriedade privada; III - função social da propriedade; IV - livre concorrência; V - defesa do consumidor; VI - defesa do meio ambiente, inclusive mediante tratamento diferenciado conforme o impacto ambiental dos produtos e serviços e de seus processos de elaboração e prestação; VII redução das desigualdades regionais e sociais; VIII - busca do pleno emprego; IX - tratamento favorecido para as empresas de pequeno porte constituídas sob as leis brasileiras e que tenham sua sede e administração no País". (BRASIL, CRFB, 1988).

${ }^{17}$ Ao abordarem o processo de busca pelo desenvolvimento sustentável, Silveira e Pereira (2018, p. 924) destacam que: “[...] os Objetivos de Desenvolvimento Sustentável são reflexos do atual estágio dos direitos humanos globalmente considerados, seja porque consistem numa reafirmação do rol de tais direitos, seja porque trazem metas concretas com a finalidade de alcançá-los e protegê-los. [...] alguns objetivos e metas consistem verdadeiramente em reiterações de direitos civis e políticos e direitos econômicos, sociais e culturais já consagrados (direitos de primeira e segunda geração). Outros, dizem respeito às formas de implementação de tais direitos, notadamente os sociais, dispondo sobre meios concretos para se alcançar o desenvolvimento sustentável, inclusive no que toca a questões financeiras, de disponibilização de crédito e de crescimento econômico dos países, consistindo assim em preceitos relativos aos direitos de terceira geração".
} 
igualdade de oportunidades; b) a proteção contra fome; c) a moradia; d) de dispor de recursos naturais; e) de estabelecer relações comerciais e financeiras convenientes; f) a desfrutar dos serviços de saúde; entre outros (SILVEIRA, 2006).

Em verdade, a Constituição Federal Brasileira foi construída sistematicamente para atribuir um diálogo interpretativo de valores que embora não descritos em conjunto, servem como instrumento para a busca de justiça social, da proteção da dignidade humana, erradicação da pobreza e redução de desigualdade, que inclusive são princípios e objetivos da República (BRASIL, CRFB, 1988).

Na perspectiva humanista, é possível inferir que a sua aplicação não se remete apenas - no texto constitucional - à ordem econômica, porquanto para se analisar a dignidade humana, justiça social, proteção da propriedade privada, redução de desigualdades, entre outros princípios descritos no artigo 170, da Constituição Federal, é elementar uma sintetização e adequação dos demais sistemas e instituições do Estado, que não necessariamente por meio da ordem econômica.

É essa vertente além do direito econômico que o presente trabalho destacará, haja vista compreender que o humanismo impõe também uma delimitação ética no exercício das atividades do particular e do Estado em meio à matéria de tributação.

\section{A FUNÇÃO SOCIAL DO TRIBUTO E A IMPLEMENTAÇÃO DE UM ESTADO ÉTICO FISCAL}

Após o período da segunda guerra mundial, a ciência do direito passou por um processo de funcionalização e de reconhecimento da existência de valores universais que deveriam permear seu conteúdo, de modo que se rompeu com uma teoria eminentemente normativa e adotou-se como direito a confluência entre fato social, valor e norma, dando azo a um paradigma pós-positivista.

A partir daí, exigem-se de normas, atos do Poder Público, institutos jurídicos, entre outros, o cumprimento de uma função social. Essa função, na ótica de Duguit (2009), remetese muito em razão do reconhecimento de que o ser humano possui direito pela sua condição de ser gregário, razão pela qual tem obrigações a cumprir com a sociedade. Nesse sentido, ele é detentor de direito porque precisa atender obrigações com o meio social que é inserido (SANTOS; OLIVEIRA, 2016).

A ideia de Função Social do Direito (FSD) pressupõe uma solidariedade dos agentes entre si, ou seja, “[...] todos têm deveres para com todos, mas ninguém tem direito algum 
propriamente dito, já que ninguém tem outro direito senão o de cumprir sempre o seu dever" (SANTOS; OLIVEIRA, 2016, p. 112). Por isso, direitos como o de propriedade, por exemplo, são justos na medida em que são limitados por funções sociais impostas que atendam um interesse coletivo, e cumpram com a ordenança constitucional vigente, que permeia não apenas a ordem econômica, mas, como já dito, toda a ciência jurídica.

Pautado nessa perspectiva, reconhece-se também que o tributo possui uma função social relevante, que impõe deveres não apenas à Administração Tributária, mas também aos contribuintes. Importa observar a existência de uma via de mão dupla na qual se exige uma atuação coletiva dos agentes para atendimento dos objetivos do Estado na preservação da dignidade humana, que nesta circunstância perpassa, por óbvio, as três primeiras dimensões dos direitos humanos: a liberdade negativa ( $1^{\text {a }}$ dimensão), pois delimita o exercício de poder de tributar do Estado no alcance do patrimônio dos contribuintes (não confisco); a liberdade

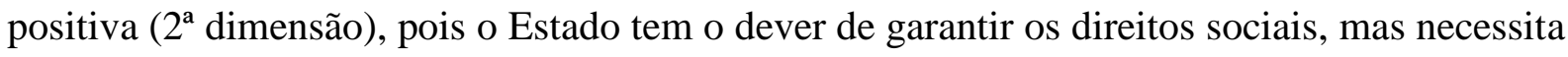
do auxílio dos contribuintes no recolhimento do tributo, que é a sua principal fonte de renda e; proteção de patrimônios difusos ( $3^{\text {a }}$ dimensão), como é o caso do meio ambiente, em que necessita de cooperação horizontal no direito doméstico e internacional para sua concretização; e o direito tributário pode ser utilizado, para tanto, como instrumento indutor de comportamentos benéficos para a tutela do meio ambiente ${ }^{18}$.

Em razão da transcendência da tributação com as dimensões dos direitos humanos, é que se recorre ao objeto da quarta dimensão - ética - para se sobrelevar a importância de uma comunicação mútua e da formação de um Estado Ético também no exercício da tributação. Isto porque, considerando que o tributo se trata de prestação pecuniária compulsória cujo objetivo se volta a garantir um bom funcionamento do Estado visando o bem comum, tem-se o dever comum da Administração Tributária e dos contribuintes na formulação de uma justiça social e fiscal.

Essa situação está de acordo com a ética da responsabilidade proposta por Hans Jonas, que busca a identificação de um novo imperativo ${ }^{19}$ que norteie as ações para que sejam

\footnotetext{
${ }^{18}$ Sobre essa função promocional do direito tributário para a preservação do meio ambiente, Silveira e Jaques (2019) salientam que: “[...] tem-se no direito tributário, por meio da tributação ecológica, seja em relação aos impostos ecológicos ou ao uso da extrafiscalidade como meio de intervenção do Estado na proteção do meio ambiente, um instrumento apto e mais eficaz do que o modelo tradicional de direito sancionatório e desincentivador de condutas.

${ }^{19}$ Para Hans Jonas a ética tradicional circundava apenas dentro dos limites do ser humano (individualismo), não afetando a natureza das coisas extra-humanas, de modo que o entendimento da ética tinha a ver apenas com o presente, exteriorizando-se do individual para o coletivo, enquanto que correto seria partir de um sentimento coletivo para à coletividade. Sua preocupação não é meramente destinada a observar o perigo da pura e simples destruição física da humanidade, mas sim na sua morte essencial, aquela relativa à desconstrução de seu ser (JONAS, 2006, p. 18).
} 
positivamente no sentido de "[...] incluir em suas escolhas presente a futura integridade do homem como um dos objetos do teu querer", haja vista que "[...] somente uma ética fundada na amplitude do ser pode ter significado" (JONAS, 2006, p. 16-17, 48). Em outras palavras, o significado da existência humana encontra sentido quando realizados atos cujo teor propicie justamente a continuidade da existência humana de maneira digna. Assim, a adoção de uma ordenança ética para a tributação é importante porque possibilita um agir coletivo com um bem público e com a preservação de direitos humanos, em especial os sociais.

Nessa linha de pensamentos que se defende a adoção de uma perspectiva ética e humanista para a instituição de um Estado Fiscal, que seja capaz de relacionar o contribuinte no centro da concretização dos direitos humanos a partir de sua própria atuação em conjunto com o Estado.

Para o Estado, seu maior desafio circunda o dever de que o recolhimento por meio da tributação não detenha unicamente o caráter arrecadatório, mas sim social, de modo que o aproxime dos seus tutelados. Isto porque, a arrecadação de tributos é a maneira pela qual o Estado intervém em meio ao campo econômico e em favor da sociedade para cumprir com seus objetivos, que é a construção de uma sociedade livre, justa e solidária; garantir o desenvolvimento nacional; erradicar a pobreza e a marginalização; reduzir as desigualdades sociais e regionais e; promover o bem de todos. (BRASIL, CRFB, 1988).

Com a finalidade de identificar uma atuação ética do Estado para exercício da tributação, podem ser destacados - sem prejuízo de qualquer outros - três fatores elementares de concretização, que estabelecem um diálogo direto com os contribuintes, para a proteção interdimensional dos direitos humanos: i) proteção do mínimo existencial no exercício da tributação, o que auxilia na garantia dos direitos sociais e na não invasão do patrimônio do contribuinte de maneira confiscatória; ii) a utilização das normas tributárias como instrumentos indutores de comportamentos benéficos para o desenvolvimento ambiental e; iii) a simplificação das obrigações instrumentais e uma atuação moral entre os representantes da Administração Tributária e os contribuintes.

Em relação à primeira ideia de ética na tributação, tem-se o dever positivo do Estado em organizar-se administrativa e juridicamente no sentido de estruturar um sistema tributário cujo ponto principal de atuação esteja pautado no próprio ser humano, para o fim de atender todas as demandas imprescindíveis à consecução dos direitos fundamentais e da dignidade da pessoa humana.

Com isso ganha força a ideia do mínimo existencial, que, conforme os ensinamentos de Sarlet e Figueiredo (2008, p. 25), se consubstancia no “[...] núcleo essencial dos direitos 
fundamentais sociais, [...] blindado contra toda e qualquer intervenção por parte do Estado e da sociedade". Em outras palavras, referida teoria tem como base a dignidade da pessoa humana, na qual configura como sendo corolário da capacidade econômica baseada no princípio da igualdade e da justiça social. Para assegurar os direitos sociais, tem o Estado o dever de ofertar condições mínimas, independente do meio utilizado, ao cidadão, para que ele possua bens materiais mínimos indispensáveis à sua sobrevivência com dignidade e, por óbvio, de sua família (TORRES, 2009).

Nesse sentido, o mínimo existencial em matéria tributária, conforme os ensinamentos de Vasconcelos (2012, s/p), traduz-se “[...] na proibição constitucional de o Ente Público tributar a parte do patrimônio do indivíduo, utilizada exclusivamente para satisfazer às necessidades elementares de sua existência e também a de sua família”, estando essa situação intrinsecamente relacionado à ética e à responsabilidade na tributação, justamente porque representa limitações ao Estado no exercício do poder de tributar e o auxilia na garantia intergeracional da dignidade humana dos contribuintes, eis que a tutela dos direitos sociais implica no aumento da qualidade de vida.

Essa ideia decorre da interpretação harmônica das normas tributárias coligadas aos postulados Constitucionais, cujo objetivo precípuo volta-se à construção de uma justiça social e fiscal baseada na dignidade da pessoa humana. Sobre o assunto, elucida Carrazza (2005, p 98) que o mínimo existencial está diretamente relacionado ao princípio da capacidade contributiva, na qual se trata de instrumento limitador do poder de tributar do Estado.

Como bem leciona Baleeiro (2004, p. 276), “[...] a capacidade contributiva do indivíduo significa sua idoneidade econômica para suportar, sem sacrifício do indispensável à vida compatível com a dignidade humana, uma fração qualquer do custo total de serviços públicos”. Portanto, poderá se falar em exercício de tributação em havendo capacidade contributiva por parte do contribuinte, que apenas será considerada após identificar o atendimento ao mínimo existencial, consubstanciado em, por exemplo, “[...] um bem jurídico que expresse aptidão para satisfazer a uma necessidade básica, elementar para a sobrevivência do ser humano" (VASCONCELOS, 2012, s/p).

Por esse motivo a capacidade contributiva deve ser detidamente observada, com a finalidade de impor uma perspectiva ética e humanista nas funções do Estado, bem como de reconhecer o ser humano no centro da atividade do Estado.

Em segunda abordagem para uma atuação ética do Estado no exercício da tributação, tem-se a instituição dos chamados tributos ecológicos. Em singelas palavras, o Ente Tributante 
vale-se da sua competência constitucional para incentivar condutas que sejam benéficas à tutela do meio ambiente (objeto da $3^{\text {a }}$ dimensão dos direitos humanos).

Essa situação, inclusive, caminha de acordo com o inciso VI, do artigo 170, da Constituição Federal, que exige para a ordem econômica uma atuação que vise a " [...] defesa do meio ambiente, inclusive mediante tratamento diferenciado conforme o impacto ambiental dos produtos e serviços e de seus processos de elaboração e prestação" (BRASIL, CRFB, 1988). Assim, a tributação indutora, como bem prelecionam Silveira e Jaques (2019) é "[...] benéfica porquanto impõe, ainda que maneira indireta, uma atuação cooperativa entre o Estado e contribuinte na preservação do meio ambiente", em que a partir da ideia de função promocional do direito haverá a recompensa para quem auxiliar na preservação do meio ambiente.

Em linhas gerais, busca-se uma tentativa de conciliar a tributação, as finanças públicas, a economia e o meio ambiente, capaz de colocar nas atividades do Estado a preocupação do meio ambiente, justamente porque seus efeitos são percebidos de modo intergeracional. Essa atuação em uma perspectiva ética reconhece a necessidade de intervenção do Estado no domínio econômico para requerer que agentes poluidores se adéquem a uma preocupação da comunidade internacional e brasileira, que é o meio ambiente.

Nesse sentido, por meio de uma preocupação ética e responsável no exercício da tributação, pode o Ente Tributante valer-se da extrafiscalidade ${ }^{20}$ do tributo para diminuir ou aumentar base de cálculo e/ou alíquotas de tributos com a finalidade de induzir certo comportamento do contribuinte (CARRAZZA, 2013) e incentivá-lo a também participar da proteção ao meio ambiente, com atos que possam repercutir não apenas na sociedade atual, mas também nas futuras gerações.

O terceiro e último ponto necessário para implementação de um Estado ético fiscal e humanista permeia em uma atuação moral dos Entes tributantes, que requer, para tanto, uma simplificação das normas tributárias e a aproximação de seus agentes dos contribuintes, para auxiliá-los quando necessário, porque “[...] a questão da moralidade vincula-se, sempre, com a finalidade da atuação e qualidade dos meios empregados ao seu atingimento" (MALERBI, 1998, p. 56) pela Administração Pública.

\footnotetext{
${ }^{20}$ Ao analisar a extrafiscalidade como instrumento da tributação ecológica, Bernardi (2008, p. 16-17) leciona que: "Por meio da extrafiscalidade tributária, tendo como instrumento os benefícios fiscais, pretende-se alterar comportamentos humanos por intermédio da exação tributária. Porquanto, valendo-se dos incentivos fiscais, podese desestimular comportamentos nocivos ao meio ambiente, os quais podem ser mudados não através da utilização de novos tributos a serem aplicados aos comportamentos causadores da degradação, mas sim utilizando-se da "sanção premial", para aqueles setores que mudarem suas atitudes, implementando novas tecnologias, com o objetivo de ir ao encontro do desenvolvimento sustentável, que somente poderá ser alcançado com uma política pública que fomente e incentive os setores produtivos, premiando aqueles que contribuem na trilha deste caminho e punindo os que teimam em praticar atividades que venham a degradar o meio ambiente em níveis insuportáveis.
} 
Ao ser compreendido o direito enquanto fato social, valor e norma, é importante a ponderação que a inobservância de regras morais e/ou éticas deslegitimam também a atuação do Estado, porquanto ele não pode adotar “[...] na vivência da relação tributária nenhum comportamento contrário ao direito (MACHADO, 2009, p. 223); ou seja, o desrespeito à valores que orientam sua condução (artigo 37, da CRFB) também representa ofensa à dignidade humana $^{21}$ porque, com bem alertou Marshall (1819) no julgamento do caso McCulloch v. Maryland "[...] the power to tax involves the power to destroy"22,

É por isso que Martins (1998, p. 21) destaca que a “[...] moralidade pública constituise, pois, no mais relevante princípio a ser seguido pelos agentes do erário, em suas relações com o contribuinte", porque induz uma atuação preventiva e orientativa no cumprimento de obrigações instrumentais ao recolhimento de tributos ${ }^{23}$ :

Tal concepção, em matéria tributária, leva evidentemente a uma atuação do Fisco em orientar o contribuinte, mais do que persegui-lo, de exigir os tributos devidos de forma não vexatória, de devolver sem procrastinações as quantias que a título de tributo arrecadou indevidamente, a gerar leis que não sejam confiscatórias, nem políticas tributárias desarrazoadas, assim como não provocar publicidade indevida sobre a vida dos pagadores de tributos, visto que, de rigor, são servidores sustentados pelos contribuintes, a quem devem servir (MARTINS, 1998, p. 21-22).

Nesse sentido, a simplificação das obrigações tributárias e o auxílio do Estado no atendimento delas implica em uma perspectiva ética para sua atuação, porquanto estabelece uma relação de proximidade com o contribuinte. Exige-se, portanto, um desempenho do Ente Público na ordem econômica não apenas na condição de regulador das relações, mas também para assumir um papel ativo para uma educação tributária.

Com base nas três frentes indicadas é possível delimitar uma atuação ao ética e responsável ao Ente tributante que pode conduzí-lo ao desenvolvimento. Isto porque, em primeiro momento parte-se da importância em reconhecer que certos valores não podem ser objetos de tributação, pois são elementares à concretização dos direitos humanos de seus tutelados. Também, a ideia de orientá-los quanto cumprimento dos deveres instrumentais é de

\footnotetext{
${ }^{21}$ Segundo Malerbi (1988, p. 54) a moralidade em matéria tributária deve ser entendida como ordenança para o Fisco, porque o "[...] o direito tributário também se rege por princípios e normas de direito administrativo, adotados, em sua inteireza, as suas categorias, institutos, técnicas de controle e de tutela". Somente a partir deste entendimento que será possível "compreender a força e o valor normativo de um direito tributário concreto, historicamente situado, por intermédio de um sistema conceptual que ilumina os limites e possibilidades de uma investigação científica sobre o direito tributário".

${ }^{22}$ Tradução: "O poder de tributar envolve o poder de destruir".

${ }^{23}$ Como exemplo, Gonçalez (1998, p. 158) destaca que: "Os agentes fiscais devem pautar o seu comportamento com lealdade e boa-fé. Muitas vezes a simples falta de uma obrigação acessória, que não redunda em prejuízo do erário, pode trazer complicações ao contribuinte. O agente fiscal, se for leal, deverá dar um prazo para que o contribuinte regularize a falta. Todos sabem que a legislação tributária brasileira é pródiga em estabelecer obrigações acessórias e, na maioria das vezes, os contadores se perdem com tantas declarações, guias, documentos, procedimentos, etc".
} 
suma importância, pois o auxilia na proteção de seu patrimônio. Por fim, o Estado deve atuar também de maneira ativa/positiva, investindo em mecanismos capazes de induzir os contribuintes à proteção do meio ambiente.

Essa percepção de Estado Ético fiscal estabelece um diálogo direto, a partir da quarta dimensão dos direitos humanos, com as classificações anteriores. E por ser um dever conjunto de atuação (vertical e horizontal), vincula também os agentes privados no cumprimento de seus objetivos e na imputação de um caráter ético e humanista nas atividades relacionadas à produção de capital e riquezas.

\section{CONCLUSÃO}

No decorrer da pesquisa foi possível verificar que o processo de resistência a poderes presente na dinamogenesis dos direitos humanos resultou no reconhecimento de uma classificação que exige, não apenas de modo vertical, mas também horizontal, uma atuação ética e responsável de todos os agentes para a proteção de valores caros à sociedade atual e também às futuras gerações. Assim, compreendeu-se ser um dever coletivo que vincula o Estado e também todos os demais agentes privados, em se adotar condutas capazes de estabelecer uma relação e um diálogo de proteção com os direitos de primeira, segunda e terceira dimensão.

$\mathrm{Na}$ perspectiva do Estado, viu-se que a evolução do direito econômico e sua internacionalização no direito doméstico pressupõe uma perspectiva humanista, pois influencia o sistema capitalista por meio de um valor axiológico de carga intensa, que é a dignidade humana. Nessa linha, verificou-se o dever do Estado em atribuir funções sociais às suas atividades de regulação e atuação na ordem econômica e no sistema tributário, visando, sobretudo, a sustentabilidade social. Assim, vislumbrou-se ser possível que a derivação ética e responsável da quarta dimensão dos direitos humanos se direcione às atividades do Estado, sobretudo para pautar sua atuação com vistas à tutela de direitos de liberdade, de igualdade e de solidariedade.

Considerando que a problemática da pesquisa buscava identificar quais elementos eram necessários e possíveis para estabelecer um Estado ético fiscal e um diálogo recíproco de proteção das demais dimensões de direitos, destacou-se como relevante as seguintes formas de atuação: i) o respeito ao mínimo existencial, a partir da compreensão que a capacidade contributiva só emerge quando suficientes os valores percebidos para a concretização de direitos sociais - sustentabilidade social; ii) a indução de comportamentos benéficos à proteção 
do meio ambiente, por meio da função extrafiscal do tributo - sustentabilidade ambiental e; c) a adoção de uma atual preventiva e orientativa que aproxima o Estado dos contribuintes, para auxiliá-los em procedimentos necessários ao recolhimento de tributos - sustentabilidade econômica.

No que tange ao primeiro elemento, identificou-se que para a implementação de um Estado ético e fiscal é necessária a preservação de direitos sociais de maneira alternativa à promoção de políticas de inclusão, ou seja, ao invés de se adotar uma postura de concessão de direitos, o Estado pode caminhar em sentido oposto, e portanto, se abster de tributar valores necessários à concretização de direitos sociais ( $2^{\mathrm{a}}$ dimensão).

Em relação à segunda proposição, extraiu-se que a tributação ecológica, por meio da função extrafiscal do tributo, se trata de alternativa inteligente para a proteção do meio ambiente, porque busca premiar contribuintes que colaborem com a proteção desse patrimônio difuso da humanidade, que é objeto da terceira dimensão dos direitos humanos.

Em relação ao terceiro elemento, que se consubstanciou em um indicação de atuação da Administração Tributária para orientar e auxiliar o contribuinte, viu-se uma relação com atividade moral, na qual o Estado deve superar uma postura eminentemente sancionatória e invasiva de patrimônio (liberdade negativa na $1^{\mathrm{a}}$ dimensão) e adotar uma postura de alteridade em relação aos contribuintes.

Com base nessas indicações, viu-se que é possível delimitar uma atuação ética fiscal do Estado para a preservação de direitos humanos e de um desenvolvimento sustentável, principalmente porque essa forma é capaz de estabelecer uma relação direta e sustentável com os contribuintes.

\section{REFERÊNCIAS}

BAUMAN, Zygmunt. Globalização: consequências humanas. Trad. Marcus Penchel. Rio de Janeiro: Zahar, 1999.

BAUMAN, Zygmunt. Modernidade líquida. Trad. Plínio Dentzien. Rio de Janeiro: Zahar, 2001.

BAUMAN, Zygmunt. A ética é possível num mundo de consumidores? Trad. Alexandre Werneck. Rio de Janeiro: Zahar. 2011.

BERNARDI, Renato. Tributação Ecológica: O uso ambiental da extrafiscalidade e da seletividade tributárias. Brasília: Revista Magister de Direito Ambiental e Urbanístico, v. 3, n. 15, dez./jan. 2008.

BOBBIO, Norberto. A era dos direitos. São Paulo: Campus, 2004. 
BRASIL. Constituição da República Federativa do Brasil de 1988. Brasília: Diário Oficial da União, 1988.

BRITO, Laura Souza Lima e. Liberdade e direitos humanos: fundamentação jusfilosófica de sua universalidade. São Paulo: Saraiva, 2013.

BALEEIRO, Aliomar. Limitações constitucionais ao poder de tributar. 7. ed. Rio de Janeiro: Forense, 2004.

CARRAZZA, Roque. Curso de Direito Constitucional Tributário. 21 ed. São Paulo: Malheiros, 2005.

CARRAZZA, Roque Antônio. Curso de direito constitucional tributário. 29 ed. rev. ampl. atual. até a Emenda Constitucional n. 72/2013. São Paulo: Malheiros, 2013.

COMPARATO, Fábio Konder. A afirmação histórica dos direitos humanos. 7. ed. rev. e atual. São Paulo: Saraiva, 2010.

DUGUIT, León. Fundamentos do direito. 3. ed. São Paulo: Martin Claret, 2009.

FONSECA, João Bosco Leopoldino. Direito Econômico. 5. Ed. São Paulo: Forense, 2004.

GONÇALEZ, Antonio Manoel. O princípio da moralidade no direito tributário. In: MARTINS, Ives Gandra da Silva (coord). O princípio da moralidade no direito tributário. $2^{\mathrm{a}}$ ed. atualizada. São Paulo: Revista dos Tribunais, 1998.

JONAS, Hans. Técnica, medicina y ética. Barcelona: Paidós, 1997.

JONAS, Hans. O principio responsabilidade: ensaio de uma ética para a civilização tecnológica. Trad. Marijane Lisboa e Luiz Barros Montez. Rio de Janeiro: Contraponto, 2006.

MACHADO, Hugo de Brito. Os direitos fundamentais do contribuinte e a efetividade da jurisdição. Tese de doutorado. Programa de pós-graduação em direito da UFPE. 265 fls. Recife: repositório online do Centro de Ciências jurídicas da Universidade Federal de Pernambuco, $2009 . \quad$ Disponível em: https://repositorio.ufpe.br/bitstream/123456789/4003/1/arquivo5668_1.pdf. Acesso em: 12 ago. 2019.

MALERBI, Diva. O princípio da moralidade no direito tributário. In: MARTINS, Ives Gandra da Silva (coord). O princípio da moralidade no direito tributário. $2^{\mathrm{a}}$ ed. atualizada. São Paulo: Revista dos Tribunais, 1998.

MARSHALL, John. McCulloch v. Maryland. United States of America: 1819

MARTINS, Ives Gandra da Silva (coord). O princípio da moralidade no direito tributário. $2^{\mathrm{a}}$ ed. atualizada. São Paulo: Revista dos Tribunais, 1998.

PÉREZ LUÑO, Antonio-Henrique. ¿Ciberciudadani@@o ciudadani@.com?. Barcelona: Gedisa, 2003. 
PÉREZ LUÑO, Antonio-Henrique. Derechos Humanos, Estado de Derecho y Constitución. $10^{\mathrm{a}}$ ed. Madrid: Editorial Tecnos, 2010.

PIOVESAN, Flávia (Coord.). Direitos humanos, globalização econômica e integração regional. São Paulo: Max Limonad, 2002.

PIOVESAN, Flavia. Direitos humanos e o direito constitucional internacional. 11. ed. rev. e atual. São Paulo: Saraiva, 2010.

PIOVESAN, Flávia. Direitos humanos e justiça internacional. 2. ed. rev. atual. São Paulo: Saraiva, 2011.

SANTOS, Leonardo Caixeta; OLIVEIRA, Leandro Côrrea. A função social da propriedade imobiliária nas constituições republicanas brasileiras: da estrutura à função. In: Revista de Direito Brasileira, São Paulo, v. 14, n. 6, p. 109-127, mai/ago. 2016. Disponível em: https://www.indexlaw.org/index.php/rdb/article/view/2973/2754. Acesso em: 10 ago. 2019.

SARLET, Ingo Wolfgang. Dignidade da pessoa humana e direitos fundamentais na Constituição Federal de 1988. Porto Alegre: Livraria do Advogado, 2001.

SARLET, Ingo Wolfgang; FIGUEIREDO, Mariana Filchtiner. Reserva do Possível, mínimo existencial e direito à saúde: algumas aproximações. Revista da Defensoria Pública, São Paulo, n. 1 , jul/dez. 2008.

SAYEG, Ricardo Hasson; BALERA, Wagner. O capitalismo humanista: filosofia humanista do direito econômico. Petrópolis: KBR, 2011.

SAYEG, Ricardo Hasson; BALERA, Wagner. $O$ objetivo fundamental constitucional de erradicação da pobreza. In: Revista de Direito Brasileira, Florianópolis, v.22, n. 9, p. 66-76, jan/abr. 2019.2 Disponível em: https://www.indexlaw.org/index.php/rdb/article/view/5327/4269. Acesso em: 02 ago. 2019.

SILVEIRA, Vladmir Oliveira da. O direito ao desenvolvimento na doutrina humanista do direito econômico. São Paulo, 2006b. Tese (doutorado em direito público) - programa de PósGraduação em Direito, da Pontifícia Universidade Católica de São Paulo. 381 fls. São Paulo: Repositório da PUCSP, 2006.

SILVEIRA, Vladmir Oliveira da; ROCASOLANO, Maria Mendez. Direitos humanos: conceitos, significados e funções. São Paulo: Saraiva, 2010.

SILVEIRA, Vladmir Oliveira; PEREIRA, Tais Mariana Lima. Uma nova compreensão dos direitos humanos na contemporaneidade a partir dos objetivos de desenvolvimento sustentável (ODS). In: Revista Jurídica Cesumar - Mestrado, v. 18, n. 3, p. 903-931, set/dez. 2018. Disponível em: http://periodicos.unicesumar.edu.br/index.php/revjuridica/article/view/6942/3322. Acesso em: 10 ago. 2019.

SILVEIRA, Vladmir Oliveira da; JAQUES, Abner da Silva. O direito tributário como instrumento eficaz na busca do desenvolvimento (ambiental) sustentável. In: XXVIII Encontro 
Nacional do CONPEDI, 2019, Goiânia-GO. Anais do XXVIII Encontro Nacional do CONPEDI, 2019 .

TORRADO, Jesús Lima. Globalización y derechos humanos. Madri: Anuario de filosofía del derecho, $\mathrm{n}^{\mathrm{o}}$ 17, 2000. Disponível em: https://dialnet.unirioja.es/descarga/articulo/142424.pdf. Acesso em 30 mar. 2019.

TORRES, Ricardo Lobo. O direito ao mínimo existencial. 2. ed. Rio de Janeiro: Renovar, 2009.

TREVISAM, Elisaide; BRAGA, Julio Trevisam. IDENTITÀ NAZIONALE IN CRISI: IL CONFLITTO TRA L'EFFICACIA DELLA SFERA PUBBLICA E LA PARTECIPAZIONE POLITICA SOTTO LA PROTEZIONE DELLO STATO DI DIRITTO DEMOCRATICO. Revista Juridica, [S.1.], v. 3, n. 52, p. 129 - 147, jul. 2018. ISSN 2316-753X. Disponível em: <http://revista.unicuritiba.edu.br/index.php/RevJur/article/view/3051/371371585>. Acesso em: 25 abr. 2020. doi:http://dx.doi.org/10.21902/revistajur.2316-753X.v52i3.3051.

TRINDADE, Antônio Augusto Cançado. Tratado de direito internacional dos direitos humanos. Vol. 1. Porto Alegre: Antônio Fabris Editor, 2003.

VASCONCELOS, Inessa da Mota Linhares. A teoria do mínimo existencial e o direito tributário brasileiro. In: XXI Congresso Nacional do CONPEDI, 2012. Gioânia-Go, Anais do XXI Congresso Nacional do CONPEDI, 2012. 